\title{
Hybrid Education, Pedagogical Continuity and Instructional Efficiency amid the COVID-19 Pandemic in Cameroon Universities
}

\author{
MUKUM Cenotar Engwari (Msc) ${ }^{1}$, MATSIDA KAMTA Marcelle Annie (Msc) ${ }^{2}$ \\ ${ }^{1,2}$ Research Assistant, Ministry of Scientific Research and Innovations(MINRESI)
}

\begin{abstract}
The advent and propagation of the COVID-19 pandemic has inflicted a big blow on the manner in which knowledge is imparted and acquired across the globe. While some schools and universities have simply been shutdown, most Cameroon universities have resorted to the adoption of both online and offline ways of course delivery to students as a means to ensure pedagogical continuity. The question that arises however is, what are the impacts of hybrid education model in Cameroon universities? This study therefore examines the opportunities and challenges relating thereto. It is a mixted study, involving interviews and questionnaires. The content analyses approach was used with the help of Homi Bhabha's Hybridity theory and results revealed that in as much as instructors and learners were not adequately prepared to cope with the situation and there is an acute shortage of technological infrastructures and facilities to sustain effective teachinglearning, the COVID-19 pandemic period is disruptive in the positive sense and innovative as it has 'upskilled' and reconfigured their previous practices. From these results, it is clear that the COVID-19 pandemic period is both a curse and blessing to Cameroon university instructors and students.
\end{abstract}

Key words: Hybrid education, Pedagogical continuity, Instructional efficiency, COViD-19 pandemic, and University.

\section{INTRODUCTION}

A t the close of the year 2019, the World was hit by a virus that mankind has never experienced. This disease is said to be caused by acute respiratory syndrome, Corona virus 2 (SARS-CoV-2). It appeared in Wuhan-China and succeeded to take away the lives of a few thousand Chinese within the first fifty days of appearance and spread. It later spread worldwide; hence, calling international attention. On March $12^{\text {th }} 2020$, the World Health Organization (WHO) declared the corona virus disease a pandemic and named itCOVID-19 (Shereen and al., 2020). According to the same source, the United Nation Educational, Scientific and Cultural Organization (UNESCO) on March $18^{\text {th }} 2020$ estimated that about 107 countries had implemented national school closures due to the spread of the COVID-19 pandemic. On a whole, the pandemic has affected about 1.38 billion learners all over the world (UNESCO, 2020). The yet to be eradicated COVID-19 pandemic is severely affecting economies and educational systems around the globe. See illustration below:
COVID-19's Staggering impact on Global education

\section{COVID-19's Staggering Impact On Global Education}

Number of learners impacted by national school closures worldwide

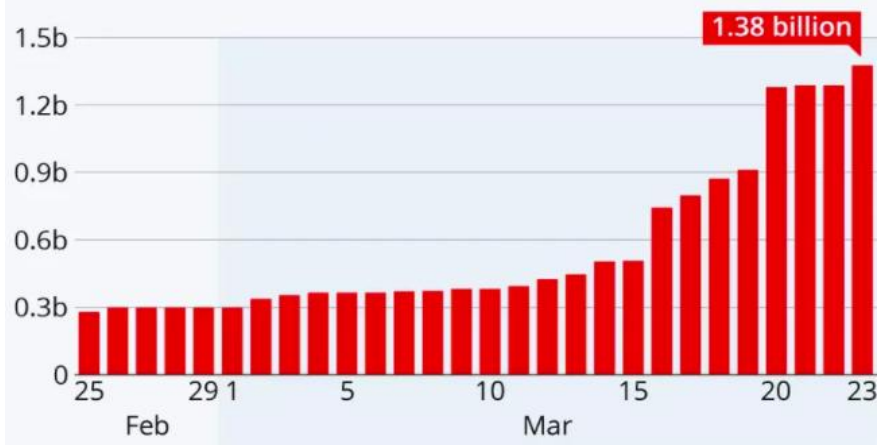

Source: UNESCO (2020).

The outbreak has indeed transformed the educational sphere within its first year of existence. The consequences of the pandemic seem to be unstoppable and uncontrollable for many countries and educational institutions. Cameroon's unreliable electricity supply poses an additional challenge to digital responses aimed at ensuring pedagogical continuity. According to Mbodiam (2019), more than $45 \%$ of Cameroonians do not have access to electricity. Rural areas, which include more than $60 \%$ of the country, are only $21 \%$ covered by the electricity network. Their populations were therefore de facto excluded from School on TV. Even urban areas are not immune to fluctuations in the electricity supply, whose high rates of load shedding reach the coast in cities such as Douala, Yaounde and Bertoua (Onana, 2020). As Andrianarison and Ehowe Nguem (2020) write, these electricity deficits have exacerbated educational exclusion and inequality in the age of COVID-19.

To that effect, most countries have put in place remote and alternative teaching-learning mechanisms so as to rescue the situation; hence, online education. According to onlineeducation.com, 2020, online education is a general concept for teaching and learning online, with the aid of technology tools and platforms. The success of online 
education depends on factors such as good internet connections, learning software, digital skills, availability and access to technology. According to the same source, online education has its roots in distance education and the emergence of digital technologies that facilitate the efficient and reliable delivery of lectures, virtual classroom sessions and other instructional materials and activities via the internet. To Onyema and Deborah, (2019), the increasing use of technology in education has modified lecturer s' methods from the traditional approach that often place them as dispensers of knowledge to a more flexible approach where they act more as facilitators, mentors and motivators to inspire students to participate and learn. They further state that technology facilitates Remote learning, Distance learning, Virtual learning, Blended learning, Mobile learning, Distributed learning, Machine learning, Ubiquitous learning, Deep learning, Cooperative and Collaborative learning. In addition, Julia N.M. E., (2017), tries to examine the problem faced by the effective supervision of dissertation in Cameroon universities in a hybrid training system due to COVID-19.

Hybrid education which is the bone of contention here has to do with the simultaneous use of both online and offline teaching-learning models in a given educational sector and context. This system of course delivery and knowledge acquisition was instituted in the said institutions at the beginning of the 2020/2021 academic year that commenced on October $15^{\text {th }}$ 2020. Cameroon universities face many challenges with this new system of learning, though there exist some advantages in acquiring knowledge. The question that arises however is, what are the impacts of hybrid education model in Cameroon universities? The hypothesis that arises from this question is that the educational system becomes more expensive and time management is more difficult for the actors. The poor internet network and insufficient access of internet the actors (lecturers and students) are unable to work or study with ease. The objective of this study is to examine the opportunities and challenges relating to hybrid system of learning in Cameroon Universities.

\section{METHODOLOGY}

Our study took place in Cameroun, particularly in the Yaounde 1 University, Center Region, the Dschang University, West Region and the Douala University, Littoral Region. The present study is a mixed study which entails qualitative methods like focus group Discussion and in-depth interviews. For the quantitative method, questionnaires and survey research design were used. It involves an in-depth exploration of opportunities as well as challenges that the new hybrid model of teaching-learning imposed by the COVID-19 pandemic stands to bring about in the context of Cameroon universities selected for this study. The research population is made up of lecturers, students and their parents. While the simple random sampling tools was used to select a total of 54 research participants; being 15 lecturers, 30 students and 09 parents. For each university, it was 5 lecturers, 10 students and 3 parents. The two methods were used on the same sample. An interview guide comprising draft questions relating to the subject matter were used to collect data from the said informants on individual and collectives bases due to the tools. Data collected was categorized following the different research variables and analyzed using the content analyses approach. This exercise was beefed up by Homi Bhabha's Hybridity theory. The Hybridity theory concerns itself with the duality of things. To Bhabha, all cultural statements and systems are constructed in a space that he calls the Third Space of Enunciation (1994:37). So, it is probable that the adoption of the hybrid model of education in Cameroon universities is liable to giving way to a new way of teaching and learning.

\section{RESULTS}

Due to the mixed Study of data collection, the results are regrouped under opportunities and challenges that accrue from hybrid education as far as instructional efficiency is concerned during the COVID-19 pandemic period.

\section{Quantitative approach}

The tools used here were questionnaires and survey research design. 54 questionnaires were administered. Among the informants, we had 15 lecturers, 30 students and 09 parents. For each university, it was 5 lecturers, 10 students and 3 parents, as analyzed on the table below:

\begin{tabular}{|c|c|c|c|c|c|}
\hline $\mathrm{N}^{\circ}$ & $\begin{array}{c}\text { Studen } \\
\text { ts }\end{array}$ & $\begin{array}{c}\text { Lecture } \\
\text { rs }\end{array}$ & Parents & \multicolumn{2}{|c|}{ Towns } \\
\hline 1 & 10 & 05 & 03 & 18 & Douala \\
\hline 2 & 10 & 05 & 03 & 18 & Dschang \\
\hline 3 & 10 & 05 & 03 & 18 & Yaounde 1 \\
\hline & 30 & 15 & 09 & 54 & Total \\
\hline
\end{tabular}

Source: Authors (March 2021).

\section{Opportunities}

Most of the informants say with the resumption of face to face and online courses students are not idle. In the study sites, 16 students, 8 lecturers and 5 parents think the hybrid education is a great opportunity for the system and for them because it has made the learning to continue. For 14 students, 7 lecturers and 4 parent say the hybrid eduction has lead them a modernized learning method which will facilitated trainings from one place, region, and country to another without necessarily travelling.

\section{Challenges}

Majority of those interviewed were of the view that hybrid education brought many difficulties. In the selected study sites, 26 students, 8 lecturers and 8 parents said hybrid learning is more expensive because of the insufficiency of money to buy computer tools, the computer rooms which are not really effective in some schools, the price and the poor internet network due to technical fault which sometimes disrupt the learning continuity. For 4 students, 7 lecturers and 
1 parent it is more tedious and tiring. There is an incompatibility between classroom and online courses for two reasons. From the onset, online students will be less presents than classroom students. Finally the two groups of leaners will not have the same understanding or the same capacity to retain information.

\section{Qualitative approach}

\section{Opportunities}

Testimonies from research participants show that hybrid education offers a lot of opportunities to instructors as well as learners. These are looked into in relation to the development of technical skills as well as learning management systems.

Hybrid education, pedagogical continuity, and the development of technological skills.

Innovation has suddenly moved from the margins to the centre of many education systems, and there is an opportunity to identify new strategies, that if sustained, can help young people get an education that prepares them for our changing times. To that effect, information from our informants shows that students retain more material when learning online as compared to when it is done in a classroom. This is due to the students being able to learn faster online. E-learning is said to require less time than in a traditional classroom setting because students can learn at their own pace, going back and re-reading, skipping, or accelerating through concepts as they choose.

Hybrid education, pedagogical continuity, and learning management systems.

Higher education courses are now delivered through learning management systems such as WhatsApp, Google Classroom, Skype, Zoom, etc. Alongside these primary institutional responses, individual and community initiatives have also flourished, with free digital resources being offered by both institutions and individuals. Students extensively use their senses to learn, making learning fun and effective through the use of technology. Clever integration of games has demonstrated higher engagement and increased motivation towards learning, especially among younger students, making them truly fall in love with learning.

\section{Challenges}

They are looked upon at the level of educational inequities and quality assurance.

Hybrid education, pedagogical continuity, and educational equalities.

Ever since a hybrid system of knowledge transmission was introduced in higher institutions of learning in Cameroon, education inequality is accelerating in an unprecedented fashion, especially where before the pandemic it was already high. Indeed, there is a gap between those from privileged and disadvantaged backgrounds. The COVID-19 crisis has therefore laid bare the educational inequalities long hidden behind the high enrolment rates so often boasted about. Several categories of learners are excluded from distance education. Those unlucky enough to be in intermediate classes, rural areas, or areas not covered by electricity are thus the forgotten ones. Many more learners were still disadvantaged despite officially being schooled due to a lack of human or digital assistance at home, be it inadequate parental support, intermittent internet access, or poor computer skills.

Students without reliable internet access and/or technology skills struggle to participate in digital learning. While campus lockdowns created an opportunity for universities to praise the originality of their innovations, in practice, these sidelined most instructors in favour of Information Technology experts and replaced pedagogical interactions with file exchange. Computer experts have therefore stepped into the central role previously occupied by instructors. Whilst they perform some functions usually carried out by instructors, such as the dissemination of teaching content, they do not possess pedagogical know-how. Distance learning is therefore characterized by pedagogical disorganization on WhatsApp and a weakening of lecturer -learner interactions in favour of file uploading on platforms.

Nevertheless, the effectiveness of online learning varies amongst age groups. The general consensus on students, especially younger ones, is that a structured environment is required, because they are more easily distracted. It was moreover agued by informants that a lot of time and cost is involved in e-learning. It is not as easy as it seems; for, a considerable amount of investment is needed for getting the devices and equipment, maintaining the equipment, training the human resources, and developing the online content. Therefore, an effective and efficient educational system needs to be developed to impart education via the online mode. Another barrier is poor digital skills among instructors themselves. The International Telecommunication Union (ITU,2019) to that effect states that less than $15 \%$ of Cameroonians command basic digital skills. Lecturer -student interaction was also hampered by Cameroon's low internet coverage, which currently stands at $30 \%$ overall and only $4 \%$ for broadband (Mbodiam,2020). While 74\% of Cameroonian households have at least one mobile phone, this is not the case for computers, social network memberships, smart phones and tablets, respectively owned by only $24 \%, 12 \%, 20 \%$ and $2 \%$ of households (Idem). The average purchase price of a Smartphone in Cameroon is exceedingly high 50,000 CFA francs (76.22 Euros), well above the minimum wage of 36,270 CFA francs per month. The same is true for mobile data allowances (ITU,2019).

Hybrid education, pedagogical continuity, and quality assurance.

It has been ascertained there is a lack of standards for quality, quality control, development of e-resources, and e-content delivery. The system is also accused of reducing instructional 
and learning time, which is known to impede students' performance, with disparate impacts on different groups of students. While learning management systems are the primary means of maintaining course continuity in universities, it coexists with communication tools such as WhatsApp, which tend to distract students from learning, since educational content was forced to compete with personal conversations. Even before COVID-19 pandemic left as many as 1.5 billion students out of school in early 2019, there was a global consensus that education systems in too many countries (Cameroon inclusive) were not delivering the quality education needed to ensure that all have the skills necessary to thrive.

There has also been pedagogical chaos, coupled with technical improvisation that has led to educational disarray; not leaving out the confusion that characterizes the search for model lessons and solutions to ensure pedagogical continuity. The education system is seen to be unprepared for the shift from face-to-face to distance education, obliging individuals and communities to step into the gap left by an uncoordinated governmental and institutional response. This has led to the multiplicity of competence centers which gave the impression that any action is welcome to address the crisis. The implementation of these various responses has created an unprecedented pedagogical environment. Institutional and community initiatives, official and unofficial tools, and digital and hard supports have coexisted side-by-side, creating a confusing array of options. In WhatsApp groups, a kind of hybridization exists between educational content and conversations from private or everyday life.

\section{DISCUSSION OF RESULTS}

Hybrid education, including online and offline teaching and learning has been studied for decades. Numerous research studies, theories, models, standards, and evaluation criteria focus on course design and the quality of teaching and learning. Research on hybrid teaching and learning thus shows that they are effective only if students have consistent access to the internet and computers and if lecturer s have received targeted training and supports for such instruction. Because these needed requirements for effectiveness have been largely insufficient for many higher education instructors and students in Cameroon, remote education during the COVID-19 pandemic period has impeded teaching and learning; hence, the introduction of hybrid education. Indeed, the pandemic has exacerbated well-documented opportunity gaps that put low-income students at a disadvantage relative to their betteroff peers as earlier indicated. Opportunity gaps here are gaps in access to the conditions and resources that enhance learning and development. Such gaps include: access to food and nutrition, lodging, health insurance and care, financial relief measures, et cetera. One of the most critical opportunity gaps in this context is the uneven access to electronic devices and internet connection. This considerably obstructs online learning, especially on the side of learners that are economically not viable. This digital divide has in effect made it virtually impossible for the said students to learn during the pandemic period.

It has also been ascertained that the pandemic has exacerbated the limitations of standardized tests, which reward a narrow set of skills. As the discussion of successful versus unsuccessful hybrid learning reveals, there are multiple requirements needed for hybrid education to work as intended and deliver positive results in the Cameroon universities. Just as the requirements for effective student learning have largely not been met during the pandemic, the same is true for effective instruction. There has been little time to design and develop instructional tools for wide deployment. As one of our informants asserted:"effective hybrid learning results from careful instructional design and planning, using a systematic model for design and development." The design process and the careful consideration of different design decisions therefore have an impact on instructional efficiency. It is this careful design process that is absent in most cases in this instructional paradigm shift. (Hodges et al. 2020).

However, it is seemingly hard to plan and to design effective instruction for the COVID-19 era when schools and instructors do not have a framework to accommodate what they are doing. As Hodges et al. (2020) emphasized when exploring how colleges and universities were coping with the sudden and rapid shift to remote learning (in March 2020), understanding the current circumstances requires conceptual clarifications. In the present context, online and offline (hybrid) education which helpclarify uncertainties and unknowns canguide instructors as well as learners' comprehension. It should also be noted that weak systems of support, including lack of professional development on how to integrate computers into instruction, have left instructors less than optimally equipped to teach during the pandemic. Inadequate systems for tracking attendance online too leave instructors in the dark on a key input of education which is students' learning time. Even the well-trained instructors when it comes to online instruction will notbe effective if their students are not online and following instruction.

Problems associated with emerging instructional designs are therefore many and varied. They range from downloading errors, issues with installation, login problems, problems with audio and video, and so on. Sometimes students find online instruction to be boring and unengaging. It involves so much time and flexibility that students find it difficult to acquaint. Students prefer two-way interaction with their instructors, which in this context becomes difficult to go by. In this type of situation, the learning process cannot reach its full potential. This can only happen if students practice what they learn and given that online content is usually theoretical and does not let students practice and learn effectively, the need for offline education becomes imperative. No matter the situation, mediocre course content is also a major issue to deal with. Most students tend to feel that lack of face-to-face interactions, technical problems, and difficulties in understanding instructional goals are the major barriers for 
online learning. This assertion is in line with that of Song et al., (2004).

\section{CONCLUSION AND RECOMMENDATIONS}

\section{Conclusion}

Challenges throughout the COVID-19pandemic period are immense and stressful; but many higher educational instructors and students are of the opinion that it is innovative as they have developed new technological skills. They have become up skilled and have reconfigured their previous teaching-learning practices. It is said to be disruptive in the positive sense in that it serves as a catalyst for change and innovation. For instance, the new hybrid way of teachinglearning is seen by informants as spurring the development of practice, particularly the re-thinking of approaches to personal pedagogies, means of learning development, and in-depth relationships with learners. This notwithstanding, findings have shown that educational systems were not adequately prepared to cope with the current situation. There is an acute shortage of structures to sustain effective teaching and learning, especially during the shutdown and to provide the safety net supports that many learners receive in school.

While the specific impacts are widely felt, it is worthwhile stating that learners' academic performance and their progress on other developmental skills are considerably being affected during the pandemic period. It is also clear that given the various ways in which the crisis has widened existing socioeconomic disparities and how these disparities affect learning and educational outcomes, educational inequities abound. As a consequence, many of the learners who were struggling the hardest way to effectively learn and thrive under normal circumstances are now finding it difficult, even impossible in some cases to sail through. They are experiencing interruptions in their learning that need to be made up for. In brief, the search for pedagogical continuity solutions in Cameroon universities is a race against time in a context that has not yet integrated distance technology as an essential training modality. The responses are a patchwork combination of institutional and individual initiatives, learning management systems and information and communication tools.

\section{Recommendations}

The evaluation of Cameroon higher educations' educational responses to COVID-19 pandemic indicates that now is the time to chart a vision for how education can emerge stronger from this global crisis than ever before and propose a path for capitalizing on education's newfound support. The options are as follows:

- Harness educational technology. Educational technology needs to be deployed to power up schools in a way that meets the teaching and learning needs of students and educators; otherwise, technology risks becoming a costly distraction in the nearest future. To get the full benefit of a new form of instruction warrants a concerted effort that goes beyond replicating an ordinary physical classroom/lecture session through video projectors to the use of collaborative tools and engagement methods that promote learners' inclusion, personalization and intelligence.

- The long overdue development of distance education, which has existed in some form for three decades already. The expansion of distance learning should be coined to focus on equipping schools and lecturer $\mathrm{s}$ with the necessary technological infrastructure and devices, training instructors and learners to use the equipment effectively, and integrating it creatively into the fabric of school life.

- The generalization of access to essential services such as electricity, television and the internet, without which the development of distance learning would be impossible.

\section{REFERENCES}

[1] Agbor E., Johanna K., and Risto R., (2017). Process of Transfer and Reception of Bologna Process Ideas in the Cameroon Higher Education System .Centre for Research on Lifelong Learning and Education (CELE), University of Turku, Finland European Educational Research Journal. pp 1-20.

[2] Al-Gahtani S.S., (2016). Empirical Investigation of E-Learning Acceptance and Assimilation: A Structural Equation Model. AppliedComputing and Informatics. 12(1): pp. 27-50.

[3] Almaiah M.A., and Almulhem A., (2018). A Conceptual Framework for Determining the Success Factors of E-Learning System Implementation Using Delphi Technique. Journal of Theoretical and Applied Information Technology, 96(17).

[4] Apongnde P., (2019). Challenges in the Effective Use of ICTs in Information Systems Management in Cameroon State Universities. PhD Thesis in Educational Management: University of Yaounde I, Cameroon.

[5] Apongnde P., (2019). Techno-Pedagogy and Graduates' Employability in Cameroon State Universities. International Journal of Research and Innovation in Social Science (IJRISS), Volume III, Issue X, October 2019/ISSN 2454-6186, pp. 536-542.

[6] Bacher H.A., Goodman J., and Mulhern C., (2020). Inequality in Household Adaptation to Schooling Shocks: Covid-Induced Online Learning Engagement in Real Time, NBER Working Papers 27555, National Bureau of Economic Research, Inc.

[7] Bellaaj M., Zekri, I., and Albugami M., (2015). The Continued use of E-Learning System: An Empirical Investigation Using UTAUT Model at the University of Tabuk. Journal of Theoretical and Applied Information Technology, 72(3).

[8] Bhabha H. K., (1994). The Commitment to Theory: Questions of Third Cinema. Ed. Jim Pines and Paul Willemen. London: BFI Pub.

[9] Julia N.M. E., (2017), Approche Hybride et Supervision des Memoires De DIPES et DIPET II: Essai d'evaluation des Activités de Tutorat Menant aux Productions des Ecrits par les Elèves Professeurs. Centre national d'enseignement à Distance, https://doi.org

[10] Krejcie R.V. and Morgan D.W., (1970). Determining Sample Size for Research Activities. Educational and PsychologicalMeasurement, 30, pp. 607-610.

[11] Moorhouse B. (2020). Adaptations to a Face-to-face Initial Teacher Education Course 'Forced' Online due to the COVID-19 Pandemic. Journal of Education for Teaching 42 (1). doi:10.1080/02607476.2020.1755205.

[12] Onyema E.M., and Deborah E.C., (2019). Potentials of Mobile Technologies in Enhancing the Effectiveness of Inquiry-Based 
Learning. International Journal of Education (IJE), 2(1), pp 1-25. https://doi.org/10.5121/IJE.2019.1421.

[13] Shereen M. A., Khan S., Kazmi A., Bashir N., and Siddique R., (2020). COVID-19 Infection: Origin, Transmission, and Characteristics of Human Coronaviruses. Journal of Advanced Research, 24, pp . 91-98. doi:10.1016/j.jare.2020.03.005.
[14] UNESCO, (2020). COVID-19 Educational Disruption and Response. $\quad$ https://en.unesco.org/covid19/educationresponse. RetrievedDec., 2020.

[15] www. onlineeducation.com. (2020). Retrieved Dec., 2020. 